\title{
PRE-PROCEDURAL RECOMMENDATIONS IN PEDIATRIC GASTROINTESTINAL ENDOSCOPY
}

\author{
Smaranda Diaconescu', Gabriela Paduraru', Claudia Olaru' ${ }^{1}$, Nicoleta Gimiga ${ }^{1}$, \\ Camelia Soponaru ${ }^{2}$, Anamaria Ciubara ${ }^{3}$, Maria Bolat ${ }^{4}$, Magdalena Iorga ${ }^{5}$ \\ ${ }^{\prime}$ Pediatrics, "Gr. T. Popa" University of Medicine and Pharmacy, Iasi \\ 2"Al. I. Cuza”, University, Iasi \\ ${ }^{3}$ Psychiatry, "Gr. T. Popa” University of Medicine and Pharmacy, Iasi \\ 4"Gr. T. Popa" University of Medicine and Pharmacy, Iasi \\ ${ }^{5}$ Psychology, "Gr. T. Popa” University of Medicine and Pharmacy, Iasi
}

\begin{abstract}
Gastrointestinal endoscopy is one of the most common invasive procedures carried out in pediatric gastroenterology and is not without risk. The range of necessary measures for the purpose of this procedure includes: the accurate assessment of the patient considering the endoscopy-related indications and contraindications, obtaining the informed consent, the psychological preparation of the parents/child, applying some dietary restrictions, and infection prophylaxis. It is also necessary to choose the type of sedation and ensure the constant monitoring during and after the procedure so as to avoid any complications related to the procedure or to the side effects of drugs.
\end{abstract}

Keywords: procedural sedation, gastrointestinal endoscopy, child

\section{INTRODUCTION}

Advances in endoscopy and anesthesia have enabled gastrointestinal endoscopies in children as early as 1960 . The last decades witnessed a significant increase in the number of endoscopies. Pediatric gastroenterologists, anesthesiologists and gastrointestinal endoscopy nurses form specialized teams that are available in various medical centers and ensure the safety and effectiveness of carrying out such procedures. Pediatric gastroenterology has established itself as a subspecialty in several countries of the European Union. The most frequently used procedures for assessing and diagnosing affections of the gastrointestinal tract are esophagogastroduodenoscopy (EDS) and colonoscopy. Wireless capsule endoscopy and double balloon enteroscopy are appropriate investigation techniques for assessing the small intestine and are the alternative to magnetic resonance enteroclysis. (1)
Procedures such as polypectomy, retrieval of foreign bodies, percutaneous endoscopic gastrostomy (PEG) placement, endoscopic retrograde cholangiopancreaticography (ERCP) or ligation of esophageal varices are therapeutic gastrointestinal endoscopy procedures that require special practical skills and technical equipment; in specialized centers, some of these procedures can even be carried out during early infancy. (1) Unlike adult endoscopy, pediatric endoscopy is usually carried out under general anesthesia in order to reduce the physical and emotional distress generated by the procedure.

\section{INFORMED CONSENT AND PSYCHOLOGICAL PREPARATION}

As with any other medical procedure, upper gastrointestinal endoscopy involves the observance of specific psychological and ethical criteria. The parents and child must give their informed consent

Corresponding author:

Gabriela Paduraru, "Gr. T. Popa" University of Medicine and Pharmacy, 16 Universitatii Street, lasi

E-mail: gaby_spulber@yahoo.com 
prior to the procedure. Both children and parents must be fully informed with respect to the benefits and risks of the investigation, and the important sections must also be presented in writing. Signing the consent form enables a doctor-patient relationship that is based on trust. The consent form also represents a legal document. In our country, obtaining the informed consent is regulated by Law no. $46 / 21^{\text {st }}$ of January 2003 regarding the patients' right to receive information about the medical services and their application, as well as about the identity and professional status of the healthcare provider. The parents' consent is an explicit and informal authorization that automatically includes the consent/ authorization from the underage patient. While acknowledging that there are certain differences, it is currently believed that patients over the age of 7 can understand the purpose of the investigation, patients over the age of 10 can understand the risks and have the rights to refuse, and after the age of 14 they have the moral and emotional maturity, as well as the capacity to understand, the abstract thinking or hypothetical evaluation that are almost typical of an adult, thus allowing them to make responsible decisions. For patients under the age of 7-10, the parents and legal guardians are responsible for refusing or cancelling the intervention. Communication and obtaining the child's consent are influenced by the presence or absence of the child's loved ones or guardians. Special situations occur in the case of pediatric patients with defective intellectual development, with psychological disorders, in orphan children with no legal representative or in institutionalized children. Alcohol or drug-consuming teenagers or those that are part of sects, as well as other patients that are involved in emergency situations and have a bad general state that does not allow the necessary time for obtaining the due authorization from the next of kin form a special category. The informed consent is a legal document that is necessarily attached to the patient chart, bearing the signature and date. (1) Its content includes the diagnostic as completely as possible and the prognosis of the affection for which the endoscopy is performed, the type and description of the procedure, including the preliminary sedation/anesthesia, the necessity and benefits of the procedure, physical troubles, discomfort, complication severity, incidence, risks and prognosis for the affection in case of refusal. The language used by the doctor must be as clear and as simple as possible, and adjusted to the parents' capacity of understanding such language. The doctors must explain the parents in as straightforward terms as possible both the advantages and the limitations of the method. Understanding the methods and preparations for gastrointestinal endoscopy by the children and their parents allows for the procedure to be performed smoothly and elicit satisfactory results. The children require various forms of sedation in order to be cooperative and feel as comfortable as possible. The endoscopist should decide the type of anesthesia to be used based on his/her personal experience. Parents and children often have separation anxiety during the procedure. The parents' presence is necessary before the procedure, and it was also approved for the anesthesia-induction period. (2) Loss of inhibition and loss of anxiety are frequent effects during the induction stage. Informed parents can help reduce the levels of anxiety in their children. Psychological preparation for endoscopy in pediatric patients should consider the physiological, psychosocial and emotional characteristics of pediatric patients, as well as the reactivity of their parents. A clinical psychologist can assist the child and their family in order to better cope with the procedure (3). Anxiolytic drugs significantly reduce the state of psychomotor agitation in patients and their families (4). Pre-procedural counseling significantly reduces the anxiety in the patient and his/her family, eliciting a higher level of compliance on their behalf. The main factors for the family are the probability of pain together with risks of sedation and anesthesia, making the parents a lot more cautious in giving their consent. For older children, carrying out relaxation and autogenic training sessions can generate considerable effects on the little patients' behavior throughout the procedure $(5,6)$.

\section{CLINICAL EVALUATION AND PRE-PROCEDURAL INVESTIGATIONS}

Clinical evaluation and physical examination are carried out systematically, with special focus on the respiratory system. Examining oral piercings, loose teeth and enlarged tonsils is a very important part of the evaluation procedure. Special attention must be paid to children between the age of 6 and 8 , a time during which both the maxillary and mandibular central and lateral incisors are at a stage of increased mobility that precedes their falling. Teeth presenting with mobility can be cracked, fractured or dislodged during the procedures for inserting the plastic mouthpiece and keeping it in throughout the entire investigation. In the case of patients wearing orthodontic brackets, defective positioning of the mouthpiece during EDS can lead to stomatological 
accidents such as the displacement or even the removal of a bracket from a tooth. However, this is not considered severe because the bracket can be repositioned in normal conditions. As a means of protection, these patients can wear special plastic pieces applied on the teeth and fitted with a groove at the level of the braces, similar to those used by wind instrument players (trumpet, saxophone, etc.) that wear braces. Piercings or loose teeth can be accidentally dislodged and may cause subsequent complications when a foreign body gets in the patient's airways. Enlarged tonsils can induce obstructive apnea in sedated patients (7). Endoscopy is contraindicated in most cases of severe coagulopathy or other coexisting severe systemic diseases. Laboratory tests such as blood type, complete blood count, liver function tests, electrolytes and coagulation parameters are recommended for this matter. The patient should be carefully monitored and the doses of sedative drugs should be lowered in case of poor liver function. Absolute contraindications for endoscopy include cardiovascular collapse, unstable airways, deteriorating pulmonary or neurologic status, intestinal perforations, peritonitis and cervical traumas. The lack of signed and informed consent or competent medical personnel staff can lead to postponing or cancelling the endoscopy. Relative contraindications include recent gastrointestinal surgery, intestinal obstruction, coagulopathy, severe thrombocytopenia, prematurity and food intake (8). Hypoglycemic episodes in insulin-dependent diabetic can influence the optimum development of the endoscopic procedure; these patients are a priority in carrying out the endoscopy and are advised to reduce the dose of insulin the morning before the procedure. In the case of children with hematemesis, plain abdominal X-ray is necessary to make sure there are no intestinal obstructions or perforations (9).

\section{DIETARY RESTRICTIONS}

Pre-procedural fasting is necessary to reduce the risk of aspirating gastric contents during sedation. Intestinal preparation depends on the planned procedure and the patient's age. Patients should fast from solids for six hours and from liquids for two to four hours before the procedure. In case of conditions such as achalasia or gastric outlet obstruction, patients may have to fast for a longer time in order to avoid the risk of aspirating food remains from the esophagus or stomach. (10) According to the American Academy of Pediatrics and the American Society of Anesthesiologists, children should consume liquids (including breast milk, except milk formula) up to two-three hours before sedation so as to avoid dehydration. Children under six months of age can receive infant formula up to 4-6 hours and other liquids up to two hours before sedation. Patients older than six months should fast from liquids and solid foods for 6-8 hours before sedation. $(11,12)$

As far as colonoscopy goes, inadequate bowel preparation causes up to a third of all the incomplete colonoscopy procedures. (13) There are no national guidelines for colonoscopy preparation. There are several available regimens that are based on either lavage or cathartics. Both methods usually depend on the cooperation of pediatric patients. The most frequently used bowel cleansing agent for children is polyethylene glycol (PEG). PEG 3350 solution is used with a dose of $1.5 \mathrm{~g} / \mathrm{kg}$ for 4 days before the procedure, and exclusively with a clear liquid diet on day $4 .(14,15)$

\section{ANTIBIOTIC PROPHYLAXIS}

The American Heart Association (AHA) and the American Society of Gastroenterological Endoscopy (ASGE) guidelines recommend antibiotic prophylaxis (Table 1) only for certain categories of patients with a high risk of heart failure. (16) This includes patients with prosthetic valves, patients with a history of bacterial endocarditis, patients with congenital heart defects that have not been surgically fixed or that were operated during the first 6 months after the intervention, or patients with residual defects in the vicinity of the prosthesis. The following pediatric patients can also support the use of antibiotic prophylaxis: immunosuppressed children, patients that have ventriculoperitoneal shunts and patients with a central line. (17)

TABLE 1. The use of antibiotics for prophylaxis according to ASGE and AHA (2007)

\begin{tabular}{|l|c|c|}
\hline Clinical situations & Antibiotic & Dosage \\
\hline $\begin{array}{l}\text { The antibiotic can be } \\
\text { administered orally }\end{array}$ & Amoxicillin & $50 \mathrm{mg} / \mathrm{kg}$ \\
\hline $\begin{array}{l}\text { The antibiotic cannot be } \\
\text { administered orally }\end{array}$ & Ampicillin & $50 \mathrm{mg} / \mathrm{kg}$ IM or IV \\
\cline { 2 - 3 } & $\begin{array}{l}\text { Cefazolin or } \\
\text { ceftriaxone }\end{array}$ & $50 \mathrm{mg} / \mathrm{kg}$ IM or IV \\
\hline $\begin{array}{l}\text { Penicillin or ampicillin } \\
\text { allergy }\end{array}$ & Cephalexin & $50 \mathrm{mg} / \mathrm{kg}$ \\
\cline { 2 - 3 } & Clindamycin & $20 \mathrm{mg} / \mathrm{kg}$ \\
\cline { 2 - 3 } & $\begin{array}{l}\text { Azithromycin or } \\
\text { clarithromycin }\end{array}$ & $15 \mathrm{mg} / \mathrm{kg}$ \\
\hline $\begin{array}{l}\text { Penicillin or ampicillin } \\
\text { allergy or the antibiotic } \\
\text { cannot be administered } \\
\text { orally }\end{array}$ & $\begin{array}{l}\text { Cefazolin or } \\
\text { ceftriaxone } \\
\text { Clindamycin }\end{array}$ & $50 \mathrm{mg} / \mathrm{kg} \mathrm{IM} \mathrm{or} \mathrm{IV}$ \\
$20 \mathrm{mg} / \mathrm{kg} \mathrm{IM}$ or IV \\
\hline
\end{tabular}


Nevertheless, the prophylaxis of subacute bacterial endocarditis is not recommended in diagnostic endoscopy, being solely reserved for therapeutic interventions (PEG-tube placement, sclerotherapy of esophageal varices, stricture dilation, ERCP, endoscopic ultrasound-guided fine-needle aspiration biopsy) $(16,18)$.

\section{PROCEDURAL SEDATION FOR PEDIATRIC PATIENTS}

Endoscopic examinations have been documented and deemed safe for motivated children (19). Adequate sedation is an integral part of a proper endoscopic procedure, reducing both the child's anxiety and his/her pain. Inadequate sedation, on the other hand, generates discomfort in the patient and leads to an incomplete examination. Endoscopy procedures in children and teenagers are generally performed under conscious sedation or general anesthesia. The advantages of conscious sedation include the preservation of natural spontaneous breathing, as well as the airway protective reflexes during the procedure. According to the American Society of Anesthesiologists (ASA), general anesthesia is recommended for performing endoscopy procedures in pediatric patients with severe or terminal systemic diseases. (15)

Pediatric patients are a lot more susceptible to respiratory complications due to higher lung resistance and are generally less resistant to hypoxemia. Infants under seven months of age constitute a higher risk group because they are obligate nasal breathers. Respiratory infections in children with a history of bronchial hyperreactivity constitute an absolute contraindication for elective endoscopy anesthesia. Propofol anesthesia appears to be the safest and most convenient sedation method (20). The parents' presence is usually essential during the pre-procedural preparation in order to reduce the anxiety and depression in younger patients (2). Premedication using benzodiazepines proved to reduce the anxiety occurring prior to the endoscopy. Such premedication can be administered both orally and nasally (21). Midazolam can reduce the emotional stress generated by the patients' separation from their parents and makes them comfortable during the procedure (22). An advantage of midazolam is its low incidence of airway obstruction, although laryngospasm and delirium may occur occasionally. Nasal oxygen supplementation is recommended (23). Midazolam administered oral- ly is a safe and effective sedation method that significantly reduces anxiety and improves the general tolerance of children undergoing EGD (24). Other substances used for these purposes include fentanyl and remifentanil. The use of propofol has increased in recent years due to its favorable pharmacodynamic profile. The bolus dose of propofol is 1-3.5 $\mathrm{mg} / \mathrm{kg}$, followed by a titrated infusion of $0.1-0.3$ $\mathrm{mg} / \mathrm{kg} /$ minute. The use of propofol is associated with a low rate of minor adverse effects that are usually reversible and do not cause sequelae. Major adverse effects of propofol sedation are extremely rare and only occur in certain patients. Adequate case selection further mitigates these risks. A recent study has reported that the use of propofol and midazolam in pediatric gastrointestinal endoscopy was just as safe and effective as in adult patients (25). The choice of anesthesia depends on a multitude of factors such as the patient's current status, the type of procedure (diagnostic vs. therapeutic), the expected level of cooperation on behalf of the pediatric patient, the preferences of both parents and children, as well as the endoscopist's experience (26). The large scale use of anesthesia in pediatric gastrointestinal endoscopy entails the possible need for resuscitation, ergo the existence of monitoring equipment in the endoscopy procedure room. Standard monitoring should include equipments such as an electrocardiogram device, a blood pressure monitor and a pulse oximeter. In order to reduce adverse reactions to a minimum, sedative drugs should be titrated until the patients are optimally sedated. At least two assistants are required during the procedure. One assistant shall monitor the airway, assess vital signs and administer medications, while the other shall assist with the diagnostic or therapeutic endoscopy. The endoscopy room must also be fitted with a source of pressurized $100 \%$ oxygen and additional suction outlets. The resuscitation equipment must be readily available at all times, including equipment for airway intubation and a defibrillator. $(15,26)$

Some parents have more difficulty in accepting the idea of performing the endoscopy under general anesthesia, therefore the attending physician should give them a full and accurate description of the sensitivity and specificity of this method (for instance, some studies report that gastric tumors in adults have a $99.6 \%$ rate of positive diagnosis; however, there are diagnostic errors due to the defective mucosal biopsies in H. pylori infection or celiac disease). (27) 
TABLE 2. Usual doses for intravenous sedation drugs

\begin{tabular}{|l|c|c|}
\hline Medication & Doses (mg/kg) & Maximum \\
\hline Benzodiazepines & & \\
\hline Valium & $0.1-0.2$ & $10 \mathrm{mg}$ \\
\hline Midazolam & $0.1-0.4$ & $10 \mathrm{mg}$ \\
\hline Narcotics & & \\
\hline Meperidine & $1-4$ & $200 \mathrm{mg}$ \\
\hline Fentanyl & $0.001-0.005$ & $200 \mathrm{jg}$ \\
\hline Others & & \\
\hline Pentobarbital & $2-6$ & $100 \mathrm{mg}$ \\
\hline Ketamine & $0.5-2$ & \\
\hline Propofol & & \\
\hline Induction & $2-2.5$ & \\
\hline Maintenance & $0.125-0.3 \mathrm{mg} / \mathrm{kg} / \mathrm{min}$ & \\
\hline
\end{tabular}

\section{REFERENCES}

1. Friedt M., Welsch S. An update on pediatric endoscopy. European Journal of Medical Research 2013, 18:24

2. Messeri A., Caprilli S., Busoni P. Anaesthesia induction in children: a psychological evaluation of the efficiency of parent's presence. Paediatr Anaesth 2004; 14:551-556

3. Brewer S., Gleditsch S.L., Syblik D., Tietjens M.E., Vacik H.W. Pediatric anxiety: child life intervention in day surgery. J Pediatr Nurs 2006; 21:13-22

4. Mahajan L., Willie R., Steffen R., Kay M., Kitaoka G., Dettorre J., et al. The effects of a psychological preparation program on anxiety in children and adolescents undergoing gastrointestinal endoscopy. J Pediatr Gastroenterol Nutr 1998; 27:161-165

5. Tanaka K., Oikawa N., Terao R., Negishi Y., Fujii T., Kudo T., \& Shimizu T. (2011). Evaluations of psychological preparation for children undergoing endoscopy. Journal of pediatric gastroenterology and nutrition, 52(2), 227-229

6. Berkenbosch J.W. (2015). Options and Considerations for Procedural Sedation in Pediatric Imaging. Pediatric Drugs, 17(5), 385-399

7. Giles E., Walton-Salih E., Shah N., Hinds R. Routine coagulation screening in children undergoing gastrointestinal endoscopy does not predict those at risk of bleeding. Endoscopy 2006, 38:508-510.

8. Yong Joo Kim. General considerations and updates in pediatric gastrointestinal diagnostic endoscopy. Korean J Pediatr. 2010; 53(9):817-823

9. Fox V.L. Gastrointestinal endoscopy. In: Walker WA, Goulet O, Kleinman RE, Sherman PM, Shneider BL, Sanderson IRPediatric gastrointestinal disease. 4th ed. Hamilton: BC Decker Inc; 2004:1685.

10. Benaroch L.M., Rudolph C.D. Introduction to pediatric esophagogastroduodenoscopy and enteroscopy. Gastrointest Endosc Clin N Am 1994; 4:121-142

11. ASGE Standards of Practice Committee, Lee K.K., Anderson M.A., Baron T.H. et al. Modifications in endoscopic practice for pediatric patients. Gastrointest Endosc 2008, 67:1-9

12. Cote C.J., Wilson S. Guidelines for monitoring and management of pediatric patients during and after sedation for diagnostic and therapeutic procedures: an update. Pediatrics 2006, 118:2587-2602

13. Henry P.O., Jenkins J.T., Diament R.H. The impact of poor bowel preparation on colonoscopy: a prospective single center study of 10571 colonoscopies. Colorectal Dis 2007, 9:745-748

14. Pashankar D.S., Uc A., Bishop W.P. Polyethylene glycol 3350 without electrolytes: a new safe, effective, and palatable bowel preparation for colonoscopy in children. J Pediatr 2004, 144: 358-362

\section{CONCLUSIONS}

Gastrointestinal endoscopy in pediatric patients is a procedure that has been evolving in the last decades and constitutes a safe and effective diagnostic tool. Children of all ages, including premature babies, can be examined endoscopically, thus allowing for a more sensitive diagnosis of wellknown diseases (celiac disease), emerging disorders and challenging diseases (the use of ERCP in neonatal cholestasis). All the pre-procedural stages must be accurately and fully carried out so as to ultimately ensure the performance of safe and effective procedures.

15. http://www.asge.org/uploadedFiles/Publications_(public)/Practice_ guidelines/2014_Modifications\%20in\%20endoscopic\%20practice $\% 20$ for\%20pediatric\%20patients.pdf

16. Antibiotic prophylaxis for GI endoscopy, ASGE Guidelines, Gastrointestinal Endoscopy Volume 67, No. $6: 2008$

17. ACC/AHA 2008 Guideline Update on Valvular Heart Disease: Focused Update on Infective Endocarditis, J Am Coll Cardiol. 2008; 52(8):676-685

18. Hirota W.K., Petersen K., Baron T.H. et al. Guidelines for antibiotic prophylaxis for GI endoscopy. Gastrointest Endosc 2003, 58:475-482

19. Bishop P., Nowicki M., May W., Elkin D., Parker P.H. Unsedated upper endoscopy in children. Gastrointest Endosc 2002; 55:624-630

20. Van Beek E.J., Leroy P.L. Safe and effective procedural sedation for gastrointestinal endoscopy in children. J Pediatr Gastroenterol Nutr 2012, 54:171-185

21. Gozal D., Drenger B., Levin P., Kadari A., Gozal Y. A pediatric sedation/anesthesia program with deicated care by anesthesiologists and nurses for procedures outside the operating room. J. Pediatr. 2004; 145: 47-52

22. Fishbein M., Lugo R.A., Woodland J., Lininger B., Linscheid T. Evaluation of intranasal midazolam in children undergoing esophagogastroduodenoscopy. J Pediatr Gastroenterol Nutr 1997, 25:261-266

23. Hussein S.A. Anesthesia for pediatric endoscopies. Int Anesthesiol Clin 2006; 44:81-93

24. Liacouras C.A., Mascarenhas M., Poon C., Wenner W.J. Placebocontrolled trial assessing the use of oral midazolam as a premedication to conscious sedation for pediatric endoscopy. Gastrointest Endosc 1998, 47:455-460

25. Xiao D., Wang F., Wang X., Tang W., Ouyang W., Shen S. Propofol combined with midazolam intravenous sedation anesthesia in pediatric upper gastrointestinal endoscopy. Zhong Nan Da Xue Xue Bao Yi Xue Ban 2009; 34:595-598

26. Tolia V., Peters J.M., Gilger M.A. Sedation for pediatric endoscopic procedures. J Pediatr Gastroenterol Nutr 2000; 30:477-485

27. Hosokawa O., Tsuda S., Kidani E., Watanabe K., Tanigawa Y., Shirasaki S., Hayashi H., Hinoshita T. Diagnosis of gastric cancer up to three years after negative upper gastrointestinal endoscopy. Endoscopy. 1998 Oct; 30(8):669-74 